\title{
Propiedad extranjera y minería en México: el proyecto de ley minera de 1908
}

\author{
Foreign property and mining in Mexico: \\ the 1908 mining law draft
}

Óscar Sánchez Rangel

Resumen

Palabras clave

Abstract

Keywords
Departamento de Historia, Universidad de Guanajuato, Guanajuato, México

Correo electrónico: osrangel_@hotmail.com

Es Doctor en Historia por El Colegio de México. Actualmente se desempeña como profesor investigador en el Departamento de Historia de la Universidad de Guanajuato. Se especializa en Historia Económica, siglos xIx y xx. Publicación reciente: “Inversión extranjera y minería. La reactivación de la producción de plata en el Guanajuato porfiriano", en María Luna Argudín y María José Rhi Sausi (coordinadoras), Repensar el siglo xIx. Miradas historiográficas desde el siglo xx, Colección Biblioteca Mexicana, Fondo de Cultura Económica, Consejo Nacional para la Cultura y las Artes, Universidad Autónoma Metropolitana, México, 2015, p. 188-215.

Este artículo analiza una arista del proyecto de ley minera de 1908 , acerca del impedimento para que las empresas extranjeras adquirieran minas en México, por lo que quedaban obligadas a constituirse bajo las leyes mexicanas. La propuesta alarmó al empresariado, integrado principalmente por estadounidenses y sus representantes, quienes protagonizaban un período de crecimiento económico y modernización. La discusión se enmarcó en un proceso caracterizado por el aumento gradual de la intervención pública en el mercado, como una vía para abordar dificultades asociadas con la inserción de México en los flujos económicos globales.

Economía mexicana, legislación minera, inversión extranjera, código de comercio, propiedad minera

This article analyzes an aspect of the 1908 mining law draft, about the impediment for foreign companies to acquire mines in Mexico, for which they were obliged to be constituted under Mexican law. The proposal alarmed the businessmen, mainly composed of US Citizens and their representatives, who were leading a period of economic growth and modernization. The discussion was framed in a process characterized by the gradual increase of public intervention in the market, as a way to address difficulties associated with the Mexican insertion in the global economic flows.

Mexican economy, mining legislation, foreign investment,commercial code, mining property
Aprobado/Approved
Recibido/Received
8 de noviembre de 2017

28 de mayo de 2018 


\title{
Propiedad extranjera y minería en México: el proyecto de ley minera de 1908
}

\author{
Óscar Sánchez Rangel
}

En este artículo examinaremos el intento de reforma realizado en 1908 para que los empresarios extranjeros adquirieran minas en México solamente si organizaban sus compañías en este país y no en el extranjero, lo que rompía con la ley minera de 1892, que se había caracterizado por las facilidades otorgadas a los inversionistas para el acceso a la propiedad minera. A pesar de que finalmente la iniciativa de ley que entregó el poder ejecutivo al congreso eliminó esta reforma, la discusión que propició ofrece un ángulo para analizar las posibilidades y desafíos que tenía el gobierno mexicano en la búsqueda de una combinación entre el funcionamiento del mercado y la intervención del Estado, bajo las condiciones de la primera globalización económica moderna. Además, el fracaso de la propuesta fue pasajero, pues finalmente su contenido quedó integrado en el artículo 27 de la Constitución de 1917. La minería era la actividad más dinámica del sector exportador y su motor provenía del flujo de inversión extranjera, que fue clave en el proceso de modernización emprendido durante el gobierno de Porfirio Díaz (1876-1911), pero la influencia de algunas empresas mineras extranjeras se convirtió en una preocupación creciente en los círculos gubernamentales. El dominio estadounidense en las actividades minero-metalúrgicas era indiscutible, de modo que controlaban casi tres cuartas partes de la minería y más de 70 por ciento de la industria metalúrgica en México hacia la primera década del siglo xx. ${ }^{1}$ Es así que este caso permite examinar algunas aristas de la integración de las economías de México y Estados Unidos de América, en un momento en que tal proceso alcanzó una intensidad inédita.

\footnotetext{
${ }^{1}$ Garner (2013a, p. 201).
} 
Entre mediados del siglo xIx y la primera guerra mundial la mayor parte del mundo se transformó económicamente, a partir de los nuevos patrones del comercio internacional que impulsó el cambio tecnológico asociado con el proceso de industrialización en Inglaterra, al que se incorporaron posteriormente otros países europeos y Estados Unidos. Las manufacturas de estos países se abarataron y demandaron más insumos destinados a la producción y al consumo de una población cada vez más numerosa y con mayor poder adquisitivo. Los costos para el intercambio de mercancías descendieron debido al mejoramiento en los transportes y las comunicaciones, lo que facilitó el desplazamiento de personas hacia zonas menos pobladas y con abundancia de recursos naturales, de tal forma que la productividad global aumentó. Además, el patrón oro fue adoptado gradualmente por más países, con lo cual se conformó un sistema monetario que dio más certidumbre a los movimientos comerciales y financieros globales. En suma, la primera globalización económica moderna consistió en una red de flujos relativamente libres de factores globales: personas, mercancías, información, inversión directa y activos financieros, cuya intensificación ocurrió durante el último cuarto del siglo xix. Asimismo, este proceso impulsó una tendencia hacia la convergencia en los precios y el aceleramiento del crecimiento económico en países pobres, mismos que acortaron la distancia con respecto a los países más ricos. En estas condiciones, la economía latinoamericana tuvo una fuerte expansión, en la que México se insertó tardíamente, una vez que logró entrar en una senda de pacificación y modernización económica hacia principios de la década de $1870 .^{2}$

En diversos estudios se ha examinado la manera en que el gobierno de Porfirio Díaz aprovechó las condiciones que ofrecía la economía internacional para el impulso productivo, a la vez que minimizaba sus efectos desestabilizadores. Con este objetivo, el gobierno mexicano negoció con los gobiernos e inversionistas de otros países, lo que modeló la incorporación de México en la primera globalización económica moderna. Tal negociación significa que la inserción de México en los flujos económicos globales no fue consecuencia solamente de la acción de los mercados, sino que fueron relevantes los

2 Gómez (2014, p. 103, 104); Riguzzi (2009, p. 361); 0`Rourke (2001, p. 1-28). 
mecanismos de intervención y de regulación del capital extranjero, que ocuparon la agenda pública desde finales de la década de $1890 .^{3}$ Otros gobiernos latinoamericanos siguieron pautas similares para la promoción de sus intereses económicos, como Brasil y Argentina, que fijaron aranceles y subvenciones para el fomento de la industria local y la regulación de la inversión extranjera. ${ }^{4}$

En México, la estrategia gubernamental influyó en la orientación de las inversiones o estableció límites a los capitales extranjeros en casos como la determinación de tarifas comerciales que favorecieron la industrialización, la adquisición mayoritaria de la acciones de la red ferroviaria por el gobierno, entre 1903 y 1908, o las acciones para balancear los intereses petroleros norteamericanos e ingleses. ${ }^{5}$ Diversos autores coinciden en que la ley minera de 1909 se planteó con el convencimiento de que había llegado el momento de contener el control extranjero de los recursos naturales y que la continuidad de esta idea se plasmó en la Constitución de 1917.6 Sin embargo, se ha puesto menos atención en el proceso que condujo a la reforma de la ley minera, con excepción del libro clásico de Marvin Bernstein quien, respecto al intento para impedir que las compañías extranjeras adquirieran propiedades mineras, explicó que se trataba de una disposición desconcertante y sin precedentes, aunque se concentró en la discusión del proyecto en el Congreso, que ya no incluyó el artículo restrictivo. ${ }^{7}$

En la primera sección del artículo examinaremos la propuesta para limitar la adquisición de propiedades mineras a los extranjeros, que formó parte del proyecto de ley minera de 1908, cuya discusión transcurrió en medio de la crisis internacional que afectó severamente a la minería. Se identificarán los argumentos que defendió la Secretaría de Fomento a cargo de Olegario Molina para justificar la reforma, sobre todo que el tiempo de una legislación liberal había pasado y que la nueva ley sería útil para el combate de los monopolios y los

\footnotetext{
${ }^{3}$ Riguzzi (2009, p. 356, 361).

4 Haber (1999, p. 27).

${ }^{5}$ Márquez (1998, p. 407-442); Grunstein (2012, p. 207-253); Garner (2013b, p. 213).

${ }^{6}$ Velasco, et al. (1988, p. 358); Sariego, et al. (1988, p. 53); Knight (1996, p. 41); Cárdenas (2003, p. 214); Riguzzi (2004, p. 163, 183); Weiner (2004, p. 55-59); Herrera y González (2004, p. 64); Kuntz (2010, p. 336); Wasserman (2015, p. 164).

7 Bernstein (1964, p. 78-83).
} 
fraudes mineros. En la segunda sección se estudiará la oposición de los empresarios mineros a la reforma y la presión que ejercieron para suprimirla, con la advertencia de que la inversión se vendría abajo. Explicaremos que esta discusión exhibió algunos problemas de las leyes que normaban la estructura corporativa de los negocios en México, pues parte del rechazo empresarial se fundamentó en que la reforma los obligaría a sujetarse al código de comercio mexicano, que algunos empresarios consideraban defectuoso para la organización de compañías mineras. En la tercera parte abordaremos la manera en que la discusión del proyecto de ley minera trascendió hacia otros ámbitos del empresariado, por la incertidumbre que generó en torno al régimen de propiedad. Por último, trazaremos la ruta que condujo a que la reforma quedara fuera del proyecto de ley que se envió al Congreso para su discusión.

\section{El móvil de la reforma}

Una de las principales motivaciones que dieron origen a la ley minera promulgada en 1892 fue la necesidad de un marco institucional liberal, que alentara la atracción de inversión extranjera. Con el fin de dejar atrás la tradición colonial, la ley de 1892 se inspiró en tres principios liberales sobre la propiedad: facilidad para adquirir, libertad para explotar y seguridad para retener. El objetivo era que los derechos de propiedad fueran más amplios y claros, además de que que la explotación minera se realizara libremente para alentar las inversiones. El denuncio como vía de acceso a la propiedad minera se suprimió y en su lugar los inversionistas debían solicitar a la Secretaría de Fomento una concesión, sin restricciones en cuanto a la extensión territorial solicitada y cuya vigencia quedaba sujeta solo al pago de un impuesto federal. En consecuencia, la propiedad minera no equivalía a la propiedad privada, pues la falta del pago era causa para que la propiedad regresara al dominio público mediante un trámite administrativo. La legislación contribuyó al crecimiento de la producción minera, pero al mismo tiempo generó otros problemas. El mecanismo de adquisición y el bajo monto del impuesto favorecieron el acaparamiento de grandes extensiones, lo que dificultó el acceso principalmente a pequeños y medianos propietarios. Además, la ley contenía ambigüedades y contradicciones que ameritaron la 
publicación de numerosas circulares, como las dirigidas a clarificar las atribuciones de los agentes de minería de la Secretaría de Fomento, pues generaban discrecionalidad en el otorgamiento de las concesiones. Por último, en la búsqueda de una legislación de aplicación federal el resultado fue parcial, debido a que la ley de 1892 equiparó la propiedad minera con otras formas de propiedad, pero el problema radicó en que su regulación era competencia de cada estado y de los tribunales locales. Es decir, como cada estado tenía la facultad de regular la propiedad con base en sus leyes civiles y procesales, la uniformidad jurídica se hacía imposible, pues en cada espacio minero se debían atender las especificidades de las normas y tribunales locales. ${ }^{8}$

En 1907 una comisión nombrada por el secretario de Fomento, Manuel González Cosío, presentó un proyecto de ley minera que reformaba la que estaba vigente desde 1892. El proyecto retomó el principio de la legislación de 1892, que condicionaba la propiedad minera solamente al pago del impuesto respectivo, pero también introdujo varias novedades, como la obligación de los extranjeros para que solicitaran un permiso especial si deseaban adquirir propiedades mineras en los estados fronterizos. Asimismo, la Secretaría de Fomento quedó facultada para negar concesiones mineras y petroleras si consideraba que tenían propósitos especulativos o contrarios al interés público y, además, estableció la responsabildad civil de las empresas en casos de accidentes de trabajo. ${ }^{9}$ Tales novedades implicaban una mayor regulación del Estado en el proceso productivo de la minería y un replanteamiento de la relación con el empresariado. Esta postura reformista se mantuvo durante los trabajos de la nueva comisión que se encargó del estudio de la legislación minera, una vez que Olegario Molina fue nombrado ministro de Fomento, en mayo de 1907, de tal forma que el nuevo proyecto de ley minera estuvo listo al año siguiente. ${ }^{10}$

\footnotetext{
${ }^{8}$ Luna (2006, p. 309); Riguzzi (2004, p. 180, 181).

9 UT-NLBC, Primer proyecto de ley minera presentado al señor ministro de fomento por los señores ingenieros Eduardo Martínez Baca y Joaquín Ramos Lis, y licenciados Manuel Ortega Espinosa, José Luis Requena y Rodolfo Reyes, Imprenta y Librería de Inocencio Arriola, México, 1909.

${ }^{10}$ La comisión estuvo integrada nuevamente por Eduardo Martínez Baca, funcionario de la Secretaría de Fomento, además de los abogados Jorge Vera Estañol y Manuel Calero, quienes representaban en su despacho a varias de las empresas mineras, agrícolas, ferrocarrileras y
} 
La reforma de la ley minera fue parte de una reformulación sistemática del marco normativo que se realizó entre 1908 y 1910, durante la gestión ministerial de Olegario Molina, relativo a tierras, aguas, subsuelo y minas, así como de las asociaciones de productores agrícolas, lo que implicó innovaciones legislativas y el fortalecimiento de la centralización administrativa a través de la Secretaría de Fomento. ${ }^{11}$ Los ejes del proyecto de ley minera de 1908 consistieron en la ampliación de las competencias federales para la regulación de la propiedad minera y las operaciones mercantiles, así como la asignación de nuevas facultades a la Secretaría de Fomento. ${ }^{12} \mathrm{El}$ contenido más controversial del proyecto consistió en las disposiciones para la adquisición de propiedades mineras por parte de los extranjeros. Por una parte, en la misma línea del proyecto de 1907, que condicionó la adquisición de propiedades mineras en los estados fronterizos a los extranjeros, el nuevo proyecto los obligaba a solicitar un permiso especial al Ejecutivo. Pero la principal novedad que introdujo el nuevo proyecto consistió en el artículo 144, que restringió los derechos de las compañías constituidas en el extranjero al determinar que "las sociedades extranjeras son incapaces para denunciar y para adquirir, por cualquier título, en lo sucesivo, propiedades mineras o derechos reales sobre las mismas, dentro del territorio de la República Mexicana". ${ }^{13}$ Esta restricción significaba un mayor intervencionismo estatal en

petroleras más importantes del momento. Memoria presentada al Congreso (1910, p. XXVII y XXVIII).

${ }^{11}$ Zuleta (2000, p. 97).

${ }^{12}$ El proyecto de ley minera de 1908 estipuló que la propiedad minera se adquiría originariamente de la Nación, a través de un denuncio ante la Agencia de Minería. La ley reforzaba la federalización, pues los juicios serían competencia de los tribunales federales y ceñidos al Código Civil del Distrito Federal, para evitar la diversidad de las leyes civiles y de los tribunales de los estados a los que se sujetaba la propiedad. La Secretaría de Fomento podría inspeccionar y suspender el trabajo en las minas, además de que se mantuvo la responsabilidad civil de las empresas en casos de accidentes de trabajo, lo cual sería exigible de oficio. Las disposiciones que normaban el otorgamiento de privilegios para la realización de exploraciones mineras fueron derogadas. "Proyecto de ley minera de los Estados Unidos Mexicanos, presentado por el señor presidente de la República y discutido y modificado en consejo de ministros", en Memoria presentada al Congreso (1910, p. 179-206).

13 "Proyecto de ley minera de los Estados Unidos Mexicanos, presentado por el señor presidente de la República y discutido y modificado en consejo de ministros", en Memoria presentada al Congreso (1910, p. 204). 
la regulación de la propiedad minera y un cambio profundo en las prácticas de los inversionistas extranjeros, quienes se opusieron enfáticamente, además de que otros empresarios se sumaron al rechazo porque consideraron que la restricción se podría aplicar en otros campos de la inversión extranjera en México.

La elaboración y discusión de la propuesta de ley minera se realizó en medio de una coyuntura política y económica crítica. En el terreno político estaba en marcha la crisis que, ante las dificultades de la elite para resolver la sucesión de Porfirio Díaz, condujo a su caída violenta y a la revolución mexicana. Por otro lado, la economía se encontraba bajo los efectos de la crisis que se propagó a partir del pánico bancario ocurrido en Estados Unidos a finales de 1907, que provocó la caída de la actividad económica en ese país y tuvo ramificaciones internacionales importantes, sobretodo hacia Canadá y México. El flujo de capital a México se interrumpió debido a la contracción de la inversión extranjera y de los ingresos provenientes de la exportación de materias primas, especialmente minerales, cuyo mercado más importante era el estadounidense. El valor de las exportaciones mexicanas se redujo como resultado de la caída de los precios de las materias primas, principalmente el cobre, el plomo y la plata, así como el azúcar, el henequén, el algodón y el guayule, entre otros, aunque el aumento del volumen exportado lo contrarrestó parcialmente. A este cuadro crítico se agregó el efecto de la sequía por lo que, desde finales de 1907, se perdieron las cosechas en algunas regiones y el problema se extendió entre 1908 y 1909, de tal manera que fue necesario la importación de alimentos. ${ }^{14}$ Lo peor de la crisis se manifestó durante 1908 y afectó con mayor dureza el norte del país debido a la concentración de la actividad minera en esa región. La inversión comenzó a recuperarse a finales de 1908 con el repunte de la economía norteamericana, mientras que las exportaciones crecieron a partir de 1909 bajo el impulso de la minería, aunque todavía con un valor inferior al de 1907. No obstante, la importación de maquinaria mostró un comportamiento recesivo más prolongado, pues en 1910 y 1911 su valor permaneció por debajo del

${ }^{14}$ Marichal (2010, p. 75); Cárdenas (2003, p. 240). 
registrado antes de la crisis. ${ }^{15}$ La crisis contribuyó al descrédito del gobierno y en especial de los científicos, lidereados por el secretario de Hacienda José Yves Limantour, a quienes muchos responsabilizaron por la profundidad de los efectos recesivos, entre otras cosas porque la reforma monetaria de 1905 había hecho más vulnerable la economía mexicana frente a las fluctuaciones externas.

Olegario Molina presentó el proyecto de ley minera y permanentemente defendió el artículo 144; su postura como secretario de Fomento con relación a una mayor regulación del Estado sobre la actividad de los capitales extranjeros y que al mismo tiempo abriera espacios al empresariado local, guarda relación con su trayectoria empresarial y como gobernador de Yucatán, de 1902 a 1907. Precisamente, su incorporación al gabinete presidencial fue un reconocimiento de Porfirio Díaz a la fuerza política y económica regionales de Molina y de sus aliados en la península, quienes se habían enriquecido con la exportación de henequén. Molina tenía una larga experiencia como socio y competidor de las empresas extranjeras más importantes en el mercado mundial de las fibras naturales, como la International Harvester Corporation, que surgió en 1902 tras la fusión de cinco empresas que controlaban $85 \%$ del mercado de máquinas cosechadoras y alrededor de dos terceras partes del comercio del hilo de agavillar en Estados Unidos. Los miembros de la élite a la que pertenecía Molina -la "casta divina"- tenían interés en el desarrollismo porfiriano, buscaban la intervención pública en el mercado para la promoción de sus negocios y el fomento del crecimiento económico, lo que naturalmente los alejaba de una postura liberal. ${ }^{16}$

El proyecto de ley minera se hizo público en mayo de 1908 a través de las páginas de diversos periódicos como El Imparcial, de gran circulación, y El Economista Mexicano, leído principalmente por el público interesado en los asuntos de negocios. En estos diarios aparecieron artículos que apoyaban la reforma, algunos dedicados especialmente al artículo 144, y también circuló un

${ }^{15}$ En 1909 las exportaciones mineras sumaron $\$ 8000000$ por encima de las exportaciones de 1908 , pero permanecieron por debajo de los niveles de 1907 en $\$ 4000000$. En cuanto a las importaciones de maquinaria, en 1910 y 1911 los niveles permanecieron $53 \%$ y $45 \%$ por debajo del registrado en 1907. Cahill (1998, p. 805-808).

${ }^{16}$ Joseph (1992, p. 66); Carstensen y Roazen (1998, p. 210-212); Zuleta (2006, p. 243-245). 
folleto escrito por el yucateco Fernando Solis Cámara, quien un año antes había escrito una elogiosa biografía de Olegario Molina. En términos generales, la defensa de la reforma para restringir a las sociedades extranjeras el acceso a la propiedad minera estuvo conformado por tres argumentos básicos, primero, que el crecimiento económico y la estabilidad política en México favorecían la atracción de capitales, por lo que ya no se justificaba la liberalidad que había normado el funcionamiento de las compañías mineras extranjeras, segundo, que la ley contribuiría al combate de los monopolios mineros y, tercero, que los tribunales mexicanos fortalecerían sus competencias para la solución de los litigios mineros si las compañías se constituían en México.

La principal implicación del primer argumento consistía en que la reforma a la ley minera no afectaría el flujo de inversión extranjera, debido a que se consideraba un hecho innegable que tal flujo se explicaba esencialmente por las mejores condiciones económicas y políticas que se habían alcanzado en el país durante el gobierno de Porfirio Díaz. ${ }^{17} \mathrm{El}$ segundo argumento a favor de la reforma consistía en que el impedimento para que las empresas extranjeras adquirieran propiedades mineras contribuiría a la contención del creciente poder monopólico de las grandes compañías sobre ramas completas de la minería en México, un temor semejante al que había orientado la política tendiente a la nacionalización de los ferrocarriles entre 1903 y 1907. El secretario de Fomento y otros defensores del artículo 144 del proyecto de ley minera de 1908 trataron de colocar su lucha contra los monopolios en el contexto internacional, refiriéndose principalmente al debate antitrust en Estados Unidos, que figuraba entre los temas de mayor influencia en la agenda política de este país. Las concentraciones empresariales eran una tendencia internacional, pero mientras en Europa la defensa de la competencia no había sido prioritario, pues algunos gobiernos apoyaban la formación de cárteles, principalmente en Alemania, en Estados Unidos se implementó una legislación antitrust. En 1890 entró en vigor la ley Sherman, que declaró ilegales los acuerdos formales entre empresas para controlar el mercado y prohibió cualquier acuerdo entre empresas que restringiera el comercio entre los estados o con el extranjero. Los tribunales federales

17 "Exposición de motivos al proyecto de Ley Minera de 1908”, El Economista Mexicano, 4 de julio de 1908; “El gobierno y los capitales extranjeros”, El Imparcial, 27 de junio de 1908.

ESTUDIOS DE HISTORIA MODERNA Y CONTEMPORÁNEA DE MÉXICO 55, enero-junio 2018, 121-157 DOI: http://dx.doi.org/10.22201/iih.24485004e.2018.55.63797 
tomaron decisiones gradualmente con base en la ley Sherman de tal manera que, durante los gobiernos de Harrison, Cleveland y McKinley, entre 1889 y 1901, las acciones del Departamento de Justicia apenas sumaron 18, pero durante los gobiernos de Roosevelt (1901-1909) y Taft (1909-1913) aumentaron a 44 y 66, respectivamente. Así, durante la presidencia de McKinley (1897-1901) la ley fue prácticamente letra muerta y coincidió con una gran oleada de fusiones, de tal manera que 4277 firmas se consolidaron en 257 entre 1897 y 1904, cien de las cuales controlaban $40 \%$ del capital invertido en la industria. Como resultado de esta oleada de consolidaciones surgieron gigantes corporativos como U.S. Steel, American Tobacco, International Harvester, Du Pont, Corn Products, Anaconda Copper, y American Smelting and Refining. Theodore Roosevelt, en cuya presidencia se incrementaron las acciones basadas en la ley Sherman, intentó reformar la ley al final de su mandato porque estaba convencido que el gobierno debía supervisar a las grandes empresas mediante acciones administrativas, como la regulación de los precios, pero no destruirlas. En cambio, Taft buscó una participación activa de los tribunales con base en la ley Sherman, pues creía que las sanciones severas, incluyendo la disolución de las empresas, inhibiría las conductas ilegales. ${ }^{18}$

A principios del siglo xx la lista de inversionistas extranjeros en México incluía a reconocidos empresarios del capitalismo corporativo internacional, como Guggenheim, Speyer, Morgan, Bleichroeder y Rockefeller. En la minería destacaron las grandes empresas minero-metalúrgicas como American Smelting and Refining Company, Consolidated Copper, Anaconda, American Metal Company, United States Smelting and Refining, que explotaban minerales industriales y contaban con una gran capacidad para la implementación de economías de escala. Aunque con un tamaño mucho menor que estas empresas norteamericanas, las compañías británicas que operaban en México también cambiaron, pues las medianas y pequeñas compañías mineras fueron desplazadas por grandes consorcios que operaban a escala internacional, para los cuales México representaba una fracción de sus negocios. ${ }^{19}$ La Secretaría de Fomento presentó el artículo 144 del proyecto de ley minera como un instrumento para el combate

\footnotetext{
${ }^{18}$ Comín (2014, p. 476); Collins (2013, p. 2339-2348); Kolasky (2011, p. 97-104).

19 Parra y Riguzzi (2008, p. 53-55).
} 
de los monopolios y llamó la atención sobre la política antitrusts que se efectuaba en Estados Unidos, lo que también hizo Limantour para que fuera respaldada la consolidación ferrocarrilera. ${ }^{20}$

Finalmente, el tercer argumento a favor del artículo 144 consistía en que si las empresas mineras se constituían en México los tribunales fortalecerían su capacidad para actuar en los litigios, pues no habría justificación para la intervención de los tribunales o de los diplomáticos extranjeros. El cambio en la ley minera haría posible el castigo de los empresarios que cometían fraudes y que permanecían impunes porque se acogían a la protección de las leyes o a la intermediación de los gobiernos de sus países. ${ }^{21}$ Molina indicó que las dificultades para la justicia mexicana en los juicios relacionados con negocios mineros se multiplicaban si los actores eran trusts extranjeros, lo que significaba un grave obstáculo para que el gobierno limitara los abusos de estas organizaciones monopólicas, ya fuera por razones políticas o económicas, tal y como lo hacía el gobierno estadounidense. El secretario también aseguró que los juzgados fronterizos tenían que atender numerosos fraudes cometidos por aventureros quienes, al acudir a la protección de su gobierno provocaban conflictos diplomáticos. ${ }^{22}$ Entre los fraudes más frecuentes sobre los que informaba la prensa económica destacaban la venta de acciones de negociaciones inexistentes, la alteración de los balances presentados por las juntas directivas a sus accionistas, así como la manipulación del precio de las acciones y el pago de dividendos. En parte, estos fraudes eran resultado de las dificultades que tenían los inversionistas para obtener información fidedigna sobre las empresas mineras, debido a la ausencia de mecanismos en el Código de Comercio para que las juntas directivas proporcionaran información a los inversionistas y al

${ }^{20}$ Discurso del secretario de Hacienda y Crédito Público, José Yves Limantour, en la Cámara de Diputados”, 14 de diciembre de 1906, citado en Grunstein (2012, p. 217).

${ }^{21}$ The Mining and Scientific Press, 1 de agosto de 1908, citado en "Molina's defense of law supported by mining publication but opposed strenuosly by Los Ángeles Chamber of Mines, The Mexican Herald, 12 de agosto de 1908; “Compañías extranjeras y minas mexicanas", El Imparcial, 12 de junio de 1908.

22 “Exposición de motivos al proyecto de Ley Minera de 1908”, citado en El Economista Mexicano, 4 de julio de 1908; “La nueva Ley minera. Interesante carta del señor Ministro de Fomento”, El Tiempo, 26 de agosto de 1908. 
público. ${ }^{23}$ La mecánica general de los fraudes se describía de la siguiente manera en un folleto en apoyo del artículo 144:

Las sociedades extranjeras se presentan en nuestro país aparentando tener millones. Al que con ellas trata, le es difícil saber si tienen realmente el capital que parecen tener o si este es tan solo "creation of the brain" [...] después resulta que el capital no existe, viene la necesidad de seguir juicio a la compañía y como ésta tiene su domicilio fuera del país, la cosa se hace poco menos que imposible. $^{24}$

La restricción hacia los extranjeros del proyecto de ley minera de 1908 encontró campo fértil entre quienes observaban críticamente el dominio de las empresas mineras, sobre todo en regiones aisladas, en las que las administraciones frecuentemente ejercían control sobre diversos servicios básicos en las comunidades, como el agua, las viviendas de los trabajadores, el servicio eléctrico, así como los centros hospitalarios y las escuelas. De acuerdo con Alan Knight este control, y no algún factor económico, fue objeto de crítica entre grupos de clase media. Se trataba de consideraciones patrióticas y políticas, que concebían a las empresas extranjeras como enclaves que impedían la integración política nacional..$^{25}$ En sintonía con lo anterior, Toribio Esquivel Obregón, quien justo en 1908 atrajo la atención nacional por su crítica a la política bancaria del gobierno, celebró el contenido del proyecto de ley minera durante su polémica con Joaquín Casasús porque, a diferencia de la reforma bancaria que le parecía un desastre, el proyecto de ley minera se había redactado “...inspirándose en las más sanas doctrinas de la ciencia económica (...), para que el mexicano sienta en su país el orgullo de su nacionalidad y el extraño la respete...” ${ }^{26}$ El gobierno

23 Una propuesta de mediados de la década de 1890, para combatir los fraudes y ordenar el mercado de acciones mineras, fue la organización de una bolsa de valores. Chirino (1999, p. 71- 73 y 86-88); Parra y Riguzzi (2008, p. 50, 54).

24 UT-NLBC, Fernando Solís Cámara, Los artículos 141 y 144 del proyecto de ley minera, Tipografía del ingeniero Fernando Bustillos, México, 1908, p. 65.

25 Knight (1996, p. 169).

26 Toribio Esquivel Obregón, “Las reformas a la Ley de Instituciones de Crédito. Contestación al Sr. Lic. D. Joaquín D. Casasús. VIı La intervención del gobierno.”, 11 de septiembre de 
mexicano intentó que los inversionistas extranjeros aceptaran que el condicionamiento de la propiedad minera a la organización de empresas mexicanas era compatible con una postura abierta a la inversión extranjera. Sin embargo, como veremos a continuación, numerosos empresarios mineros y algunos de otros ramos recibieron la reforma como una hostilidad del gobierno mexicano.

\section{El rechazo empresarial}

A finales de mayo de 1908, Olegario Molina presentó el proyecto de ley minera a los empresarios y especialistas del ramo, y además fue difundido en la prensa. El rechazo al artículo 144 en el ámbito minero fue inmediato y la atención se concentró en este aspecto de la ley, de tal manera que algunos críticos se refirieron al proyecto como la "ley antiextranjera". ${ }^{27}$ Los integrantes de la comisión que había redactado el primer proyecto de ley minera en 1907 y varios miembros de la Cámara Minera de México, especialmente el abogado Carlos Robles, estudiaron el nuevo proyecto y coincidieron en que la restricción para que las sociedades extranjeras adquirieran propiedades mineras en México era equivocada; un miembro de la Cámara afirmó que el artículo 144 era el "golpe de gracia para la industria minera" ${ }^{28} \mathrm{El}$ presidente de ese organismo empresarial, José Luis Requena, quien también era diputado en el congreso y representante de diversas empresas mineras extranjeras, como la compañía de capital francés que operaba en Michoacán, Las Dos Estrellas, expresó al secretario de Hacienda su desacuerdo con el artículo 144. Además, Requena aseguró a Limantour que su rechazo era compartido por Rodolfo Reyes -el hijo del gobernador de Nuevo León, Bernardo Reyes, y quien había participado en la elaboración del proyecto de ley minera de 1907-. ${ }^{29}$ A diferencia de este rechazo unánime, el artículo sobre la responsabilidad civil por accidentes de trabajo fue apoyado por Rodolfo Reyes

1908, La Reforma bancaria (2008, p. 297).

27 Así se le conocía al proyecto de ley entre los miembros de la colonia estadounidense en México, según su presidente, William Vernon Backus. CEHM, AJYL, fondo CDLIV, rollo 55, carta de William Vernon Backus a José Yves Limantour, México, 26 de agosto de 1908.

28 “Los mineros discuten puntos importantes”, El Imparcial, 31 de mayo de 1908.

29 CEHM, AJYL, fondo CDLIV, rollo 55, carta del presidente de la Cámara Minera de México, José Luis Requena, al secretario de Hacienda y Crédito Público, José Yves Limantour, México, 
y otros miembros, aunque finalmente se sumaron a las conclusiones generales de la Cámara Minera de México. ${ }^{30}$ Para estos empresarios y sus representantes los argumentos a favor del artículo 144 eran insostenibles, por lo que plantearon que el flujo de capital hacia la minería mexicana se debía al cariz liberal de la ley minera vigente, que era la que prevalecía en los países más civilizados del mundo, por lo que la restricción a las compañías extranjeras provocaría desinversión. Asimismo, minimizaron la influencia de las grandes empresas extranjeras en el mercado y la frecuencia con la que intervenían los gobiernos de otros países en los litigios sobre minas, por lo que el combate a los monopolios y el fortalecimiento de los tribunales mexicanos no justificaban la reforma. Un argumento adicional que sostuvieron varios críticos del proyecto de ley minera consistió en que el artículo 144 obligaría a las empresas a constituirse de acuerdo con las legislación comercial de México, misma que consideraban deficiente, por lo que esto también ahuyentaría la inversión.

Una de las argumentaciones más completas en contra del proyecto de ley minera que se publicaron fue la de Carlos Robles, un abogado guanajuatense y miembro de la Cámara Minera de México, quien criticó el artículo 144 del proyecto de ley minera y defendió la ley vigente, con base en consideraciones jurídicas y económicas. Carlos Robles ejemplificó lo benéfico que había sido la inversión extranjera en la minería mexicana refiriéndose al centro minero de Guanajuato, que conocía muy bien por sus vínculos familiares con los mineros de la región y por su desempeño como abogado de las principales empresas norteamericanas que operaban allí. ${ }^{31}$ Robles había observado la acelerada transformación ocurrida entre finales del siglo xix y principios del xx, cuando empresarios estadounidenses compraron las principales minas, como la legendaria Valenciana. Entre 1902 y 1907, Guanajuato recibió uno de los más elevados volúmenes de inversión en el país dirigidos hacia la minería, a través de empresas constituidas principalmente en Nueva Jersey, Colorado y Nueva York, aun-

23 de mayo de 1908. Sobre la actividad de José Luis Requena como socio y representante de Las Dos Estrellas en El Oro y Tlalpujahua véase Uribe (2010, p. 173).

$3^{30}$ UT-NLBC, Fernando Solís Cámara, los artículos 141 y 144 del proyecto de ley minera, Tipografía del ingeniero Fernando Bustillos, México, p. 3.

${ }^{31}$ Blanco (1995, p. 24). 
que también figuraron algunas de Filadelfia, Arizona y Virginia, casi todas con oficinas en Wall Street. ${ }^{32}$ Robles recordó que la crisis de la minería guanajuatense había quedado atrás gracias a que la inversión extranjera posibilitó el uso de la electricidad y la cianuración, en sustitución de los antiguos métodos empleados desde el virreinato, de tal forma que ahora "reina la abundancia", aseguró el abogado.33

Los opositores a la reforma sostuvieron que esta transformación económica podía frenarse si se restringían las condiciones para la operación de las sociedades extranjeras porque la inversión disminuiría. En la prensa fueron publicadas noticias sobre negocios mineros que se frustraban y se aseguraba que obedecía a la incertidumbre generada por el proyecto de ley minera. ${ }^{34}$ Esta misma interpretación sobre la incompatibilidad de la reforma con la continuidad del flujo de inversión se observa en un informe del ministro británico en México, quien observó que el "nacionalismo mexicano autosuficiente" pretendía el control y dirección de las minas y ferrocarriles "con la expectativa de que el extranjero seguirá derramando su oro en la República, a pesar de las desventajas que entonces le impondrán”. ${ }^{35}$ El énfasis de este diplomático apuntaba hacia la condición de México como un país con escasez de capital, lo que salió a relucir en el debate público cuando los defensores de la reforma indicaron que otros países, entre los cuales figuraba Estados Unidos, imponían restricciones a las sociedades extranjeras para la adquisición de propiedades mineras, por lo que era incongruente negarle a México la implementación de una medida semejante.

${ }^{32}$ El Cónsul General Alfred Gottschalk informó que la inversión estadounidense invertida en la minería mexicana de 1902 a 1907 fue de \$64000 ooo y los principales estados receptores fueron Guanajuato (19\%), Jalisco (16\%), Oaxaca (16\%), Guerrero (8\%), Hidalgo (8\%), Puebla (8\%) y Zacatecas (8\%). Bernstein (1964, p. 73); Meyer (1998, cap. III). Para un análisis historiográfico sobre la expansión minera en Guanajuato durante estos años véase Sánchez (2015, p. 188-215).

33 Carlos Robles, “Las compañías extranjeras y el proyecto de ley minera. Sexta parte.”, El Tiempo, 15 de julio de 1908.

34 "Doing harm to Mexico. Americans make capital of mining law agitation", The Mexican Herald, 20 de julio de 1908; "Investors alarmed. Mining law agitation is injuring Mexico." The Mexican Herald, 7 de agosto de 1908; “Mining law agitation stops \$125000 deal”, The Mexican Herald, 23 de agosto de 1908.

35 Carta de Reginald Tower para sir E. Grey, 3 de julio de 1908, en Garner (2013b, p. 179). 
Las opiniones contradictorias que se publicaron en la prensa denotan que no había claridad en torno a las características de la legislación internacional en la materia, inclusive, Limantour solicitó información sobre la legislación estadounidense a Pablo Macedo, quien se encontraba en Nueva York. Macedo contestó que las sociedades extranjeras podían adquirir bienes raíces casi en todos los estados de ese país y que en su totalidad lo permitían a los individuos extranjeros. ${ }^{36}$ La diversidad de las leyes se explica porque el acceso a la propiedad minera en Estados Unidos era competencia de los estados, lo que en México fue interpretado interesadamente pues, mientras que los defensores del artículo 144 subrayaron que los estadounidenses fijaban restricciones a las compañías mineras extranjeras, los opositores sostuvieron que en ese país la tendencia también apuntaba hacia la igualdad de derechos entre ciudadanos y extranjeros. Por encima de las comparaciones con la legislación internacional, los defensores de una política liberal para la adquisición de minas insistieron en que México necesitaba capital, por lo que no había condiciones para obstaculizar el ejercicio de las sociedades extranjeras.

La explicación más concreta sobre el desplome de la inversión consistió en que si se aprobaba el artículo 144 las compañías quedarían reguladas conforme al código de comercio de México, que algunos consideraban inadecuado para la organización de compañías mineras. Este asunto ofrece la oportunidad de rediscutir la modernización de la estructura corporativa de los negocios que se alcanzó con los códigos de comercio de 1884 y 1889, sobre todo a través de la incorporación de la sociedad anónima como una opción para la organización empresarial. Si bien estas normas contribuyeron al crecimiento económico durante el porfiriato, es posible que la ausencia de una reforma que corrigiera un conjunto de problemas relativos al funcionamiento de las figuras mercantiles frenara la modernización económica y obstaculizara el desempeño económico. ${ }^{37}$ Como veremos a continuación, la discusión del proyecto de ley de 1908 puso a

${ }^{36}$ CEHM, AJYL, fondo CDLIV, rollo 50, telegrama de José Yves Limantour para Pablo Macedo, 17 de junio de 1908; telegrama de Pablo Macedo para José Yves Limantour, 19 de junio de 1908.

37 En cuanto a los problemas de las sociedades anónimas destacan el bajo porcentaje exigido para la exhibición del capital social, lo que desalentó la inversión en capital de riesgo. Además, la ausencia de mecanismos que garantizaran al público y a los accionistas informarse sobre la marcha de las empresas obstaculizó el funcionamiento del mercado financiero. Esto 
flote un aspecto de esas inconveniencias legales que podían perjudicar a las compañías mineras lo cual, aunque se había denunciado antes, no había generado una discusión sistemática.

Conviene recordar que la ley minera de 1892 obligaba a que las empresas registraran un acta notarialmente protocolizada, que indicara los datos generales de la escritura social, tales como la identificación de los socios y el capital social, así como las finalidades, alcances, limitaciones y caducidad de la sociedad, de acuerdo con lo estipulado en el Código de Comercio. Además, también con base en este código, las empresas tenían que ajustar sus libros contables, cuya revisión era facultad del gobierno. Sin embargo, no todas las empresas extranjeras que operaban en México en distintas actividades, incluyendo la minería, se ajustaban a lo indicado en el Código de Comercio, como lo han mostrado Aurora Gómez y Aldo Musacchio, quienes en su análisis sobre el Registro Público de la Propiedad y del Comercio de 1886 a 1910 identificaron un conjunto de empresas que operaban en México pero que no fueron registradas. La razón de esta decisión no es clara, pues podría deberse a que los empresarios juzgaban poco relevante que el funcionamiento de las compañías quedara fuera de la legislación comercial, pero también que prefirieran mantenerse al margen de esta ley porque así convenía a sus intereses..$^{38}$ Es posible que esto último explique que las empresas mineras organizadas en Estados Unidos optaran por no registrarse ni ajustarse a lo indicado en la legislación comercial. El gobierno mexicano aceptaba el funcionamiento de compañías mineras organizadas en Estados Unidos con la justificación de que los reglamentos comerciales de ese país eran semejantes a los de México, ${ }^{39}$ pero el artículo 144 cancelaba esta opción. Para los críticos de la reforma tal impedimento equivalía a limitar el derecho de asociación porque los empresarios estaban obligados al cumplimiento de “...una ley que no conocen y que acaso no se ajusta a las necesidades de los hombres de empresa que han de proporcionar el capital para

contribuyó al desprestigio de la sociedad anónima, sobre todo al final del porfiriato y durante la década de 1910. Gómez-Galvarriato y Recio (2003, p. 14); Riguzzi (2004, p. 176-178).

${ }^{8}$ Gómez-Galvarriato y Musacchio (2004, p. 8).

39 Meyer (1998, p. 102). 
la adquisición, fomento y desarrollo de una negociación minera ubicada en país extranjero". ${ }^{40}$

En realidad esta crítica no era nueva ni se limitaba al caso de las empresas mineras extranjeras, pues ya antes se habían escuchado posturas relativas a que la legislación sobre sociedades no contemplaba las necesidades específicas de las compañías mineras en general. En 1897 el destacado abogado Jacinto Pallares dijo que era un error que se sujetara "en globo" a las sociedades mineras dentro de los preceptos del Código de Comercio sobre sociedades mercantiles, porque estaban condicionadas por variaciones aleatorias en el contenido mineral, de tal forma que no era posible determinar el monto del capital como lo exigía el código de Comercio". ${ }^{41}$ Poco después, en 1901, Rodolfo Reyes retomó lo dicho por Pallares en un apéndice de su tesis para graduarse como abogado, en donde planteó que la sociedad de avío era el contrato más común en la minería, cuya principal ventaja era su adaptabilidad frente a contingencias como el cambio en las condiciones geológicas o las inundaciones, pues hacía posible que el capital invertido se modificara sobre la marcha. Sin embargo, este mecanismo era inaccesible porque el artículo 24 de la ley minera de 1892 prohibía las asociaciones mineras y las figuras mercantiles disponibles en el Código de Comercio imponían rigideces para la implementación de los cambios. ${ }^{42}$ Una de estas rigideces consistía en la dificultad de las empresas mineras para ofrecer una garantía a los inversionistas, a diferencia de lo que ocurría con otras empresas como las ferrocarrileras, de bienes raíces y agrícolas, que emitían bonos garantizados con tierras. En estas condiciones, las compañías semiautónomas británicas dedicadas a la minería, eran capaces de reunir capital en el mercado londinense para destinarlo hacia inversiones arriesgadas con poca garantía. De cualquier forma, más de la mitad del capital británico se concentró en el ramo ferrocarrilero y las compañías mineras semiautónomas fueron desplazadas por los grandes corporativos mineros internacionales a principios del siglo xx. ${ }^{43}$

$4^{0}$ Carlos Robles, “Las compañías extranjeras y el proyecto de ley minera. Primera parte”, El Tiempo, 9 de julio de 1908.

${ }^{41}$ Legislación Federal Complementaria (1897, p. LIX).

42 Reyes (1901, p. 42-45).

43 Liehry Torres (1998, p. 636). 
En el proyecto de ley minera de 1907, el que fue presentado antes de la llegada de Molina a la Secretaría de Fomento, se propuso una solución tendiente a compatibilizar las leyes comerciales y las necesidades de la minería con base en el diagnóstico de Rodolfo Reyes, que se incorporó casi íntegramente en la exposición de motivos del documento. Este proyecto mantuvo la obligación para que los contratos sobre operaciones mineras se rigieran bajo el Código de Comercio, pero eliminó la restricción contenida en el artículo 24 de la ley de 1892 y otorgó libertad para la formación de cualquier sociedad o asociación, de acuerdo con las normas civiles y mercantiles. Las sociedades debían registrarse mediante escritura pública, pero el cambio sustantivo radicó en que los socios no estaban obligados a la comprobación de sus aportaciones en la forma de propiedades o derechos mineros, porque se asumió que tales aportaciones eran inciertas en la minería. Dicha reforma permaneció en el proyecto de ley minera de 1908, y adicionalmente se precisaron los actos mercantiles en materia minera que regularían el Código de Comercio o el Código Civil del Distrito Federal. ${ }^{44}$ González Roa sostuvo en un libro publicado en 1915 que esta medida había sido una concesión exagerada hacia los inversionistas, porque podrían estimar el valor de las propiedades que aportaran a la sociedad sin que se realizara un avalúo, lo que abría la posibilidad para que se cometieran especulaciones y fraudes. 45

La libertad para la formación de asociaciones que consignó el proyecto de ley minera de 1908 no fue suficiente para algunos actores sobresalientes de la minería en México, como Daniel Guggenheim, el poderoso empresario que presidía la American Smelting and Refining Company (Asarco), el "trust de los fundidores”, como se le conocía en Estados Unidos. Guggenheim, se opuso al artículo 144 del proyecto de ley minera e indicó que una explicación de su rechazo descansaba en que la legislación mexicana sobre las sociedades por acciones era deficiente. A principios del siglo xx 40\% del plomo y 20\% de la plata

44 El artículo 80 del proyecto de ley minera de 1908 indicó que los actos mercantiles contemplados eran: 1) las empresas de minas, 2) los contratos que tengan por objeto la enajenación y explotación de las minas y, 3) los contratos que se celebren con relación a los productos de las minas.

45 González (1975, p. 546). 
producida en México salía de las fundiciones de la Asarco, cuya planta de Aguascalientes era la mayor en Norteamérica y en 1908 procesaba 1550 toneladas de mineral al día. Las plantas de la compañía en Estados Unidos estaban integradas con sus fundiciones en México, cuyos insumos procedían de las minas que controlaba en Sierra Mojada y en Santa Eulalia, por lo que su abstecimiento no dependía de los mineros independientes. Esta integración vertical de los procesos de extracción y refinamiento de los minerales implicó una fuerte inversión en la adquisición de numerosas propiedades mineras para el abastecimiento de las fundiciones, lo que acarreó a la empresa disputas frecuentes relacionadas con la propiedad de tierras y minas. ${ }^{46}$

Daniel Guggenhein explicó a Porfirio Díaz que el proyecto de ley minera era un peligro para sus intereses en México, especialmente por el artículo 144. El empresario sostuvo que era preferible la organización de las compañías mineras en el extranjero, pues "Si las leyes de México permitieran la organización de corporaciones con la forma acostumbrada en otros países, sería tal vez posible la organización de tales corporaciones; pero no es el caso...”, en consecuencia, decía Guggenheim, la reforma simplemente ahuyentará la inversión. ${ }^{47}$ El gobierno mexicano le respondió a Guggenheim a través de un memorándum que elaboró el secretario de Fomento por órden del presidente, que la ley no era retroactiva, por lo que la condición jurídica de sus propiedades mineras no se afectaría. Además, se le recomendó al empresario que adquiriera nuevas propiedades con base en la reglamentación mexicana o mediante el arrendamiento de minas. Sin embargo, Molina aceptó que las leyes mexicanas para la organización de las sociedades tenían deficiencias, pues distintas voces coincidían con la crítica de Guggenheim, pero la solución era que se perfeccionaran y no que se desechara el artículo $144 .{ }^{48}$ No obstante, este reconocimiento se diluía en la contestación del gobierno mexicano al presidente de la Asarco, pues

${ }^{46}$ Bernstein (1964, p. 248-251); Hoernel (1980, p. 227); Gómez (2004, p. 63).

47 UIA, APD, f. 010803 , carta de Daniel Guggenheim a Porfirio Díaz, Nueva York, 24 de julio de 1908.

$4^{8}$ UIA, APD, f. 011734, Olegario Molina, "Memorandum relativo a la carta del señor Daniel Guggenheim dirigida al señor Presidente de la República" 11 de agosto de 1908. UIA, APD, f. 013534, carta de Daniel Guggenheim a Porfirio Díaz, Nueva York, 7 de octubre de 1908. 
predominaba la defensa del proyecto de ley minera y especialmente del artículo 144, con los argumentos que hemos expuesto.

El rechazo de Guggenheim y de otros empresarios mineros al intento del gobierno mexicano por reformar las bases que regulaban la inversión extranjera en la minería contrastan con las decisiones de otros empresarios, quienes consideraron viable la formación de sus empresas de acuerdo con las leyes mexicanas. En varios artículos periodísticos relacionados con la polémica en torno al artículo 144 se mencionaron casos de empresas constituidas en México exitosamente, por lo que era falso que fuera un factor que inhibiera el flujo de capital externo. Como ejemplos se citaron a los bancos y a las empresas ferrocarrileras, además de varias empresas mineras. ${ }^{49}$ En esta línea, los estudios sobre las compañías semiautónomas británicas han mostrado que algunas se convirtieron en empresas mexicanas para resolver los frecuentes problemas asociados con la lejanía entre el consejo directivo en Inglaterra y la administración en México, como la lentitud en la toma de decisiones. Así lo hicieron principalmente las empresas en ramos intensivos en mano de obra, como las fábricas de algodón y de tabaco, no así en la minería, que requería la inversión de altas sumas antes de generar ganancias..$^{50}$

Una empresa extranjera que se transformó en mexicana fue la petrolera $\mathrm{El}$ Águila, del británico Weetman Pearson, quien constituyó la empresa en agosto de 1908, -en medio del debate sobre el artículo 144-, como parte de una estrategia para vencer a su competidor, el estadounidense Henry Clay Pierce. No debe olvidarse que un antecedente de esto fueron los contratos celebrados en 1906 entre el gobierno y la compañía S. Pearson \& Son, Limited para la exploración y explotación de criaderos de petróleo y carburos gaseosos, que obligaban a que la empresa fuera mexicana, aunque alguno o todos sus miembros fueran extranjeros, además de que la sociedad y sus integrantes quedarían sujetos a las leyes y tribunales mexicanos. ${ }^{11}$ De acuerdo con Paul Garner, la constitución

49 "El artículo 144 del proyecto primitivo de la ley minera." en La nueva ley minera (1910, p. 608); "Circunstancias que atraen los capitales extranjeros", en El Imparcial, 17 de julio de 1908; "El proyecto de una nueva ley minera. Necesidad y oportunidad de la reforma contenida en el artículo 144", El Economista Mexicano, 1 de agosto de 1908.

${ }^{50}$ Liehr y Torres (1998, p. 638).

${ }^{51}$ Cossío (2017, p. 40). 
de la Compañía Mexicana de Petróleo El Águila se explica porque Pearson entendió los objetivos de la elite política porfiriana con respecto a la construcción del Estado y la puesta en marcha de un proyecto desarrollista, además de que tenía claro el creciente rechazo del gobierno al control extranjero de los recursos del país. Una posibilidad adicional que consideró Pearson fue que la mexicanización facilitaría que en el futuro la empresa suscribiera capital en México. El plan de Pearson incluyó la incorporación de miembros de la élite porfiriana en los órganos de decisión de El Águila, una estrategia característica de su gestión empresarial..$^{22}$ Mientras Pearson mostró esa empatía con el proyecto desarrollista, la discusión de la ley minera exhibió un conflicto adicional en la relación de Guggenheim con el gobierno mexicano, pues Limantour se había opuesto al poder monopólico que construía la Asarco. ${ }^{53}$ Ahora, Molina rechazaba los reclamos de Guggenheim y le aclaraba que la ley no debía sujetarse a las exigencias empresariales sino que "el capitalista es el que debe someterse a la legislación de la Nación a donde concurre atraído por los beneficios y utilidades que la inversión del capital ofrece". ${ }^{44} \mathrm{El}$ tono imperativo de Molina puso en relieve la importancia que tenía la reforma a la ley minera en la búsqueda de mecanismos que fortalecieran al Estado con respecto a los intereses de los inversionistas, principalmente cuando ejercían una fuerza dominante en el mercado. La Asarco terminó convirtiéndose en una empresa mexicana en 1918, para ajustarse a la Constitución de $1917,{ }^{55}$ que incorporó las restricciones anunciadas en el artículo 144 del proyecto de ley minera. El extraordinario éxito que mantuvo Asarco tras su conversión es indicativo de que los temores de Guggenheim eran exagerados, aunque para definir una respuesta clara es necesario examinar más casos para dilucidar qué conflictos de las empresas mineras eran resultado de posibles

52 Garner (2013b, p. 245-252).

53 Limantour, como miembro del consejo de administración de la empresa minera Real del Monte y Pachuca, obstaculizó el avance de la Asarco hacia los centros mineros al sur de Aguascalientes. Limantour rechazó los ofrecimientos de compra de Guggenheim y prefirió vender a la United States Smelting and Rejining Company, una firma de Boston asociada a la United Shoe Machinery Company, con la condición de que Guggenheim jamás tuviera algún interés en la empresa. Bernstein (1964, p. 52); Hoernel (1980, p. 229).

54 UIA, APD, f. 011734, Olegario Molina, “Memorandum relativo a la carta del señor Daniel Guggenheim dirigida al señor Presidente de la República”, 11 de agosto de 1908.

55 Wasserman (2015, p. 162). 
deficiencias en las leyes sobre sociedades mercantiles y si la naturaleza de tales problemas variaba en función de su tamaño en el mercado.

Los opositores de la reforma sostuvieron que el verdadero desafío para México era que se mantuviera la confianza entre los inversionistas extranjeros y no los monopolios, los fraudes mineros o la posible intervención diplomática. Afirmaban que dichas intervenciones no eran recurrentes y que las leyes sobre extranjería bastaban para que los extranjeros se sujetaran a los tribunales mexicanos. Desde esta perspectiva, los monopolios no significaban un problema real sino una "simple quimera", como afirmó Carlos Robles. ${ }^{56}$ Para Robles el debate antitrust en Estados Unidos era un fenómeno distante de México, principalmente al referirse a la minería mexicana, que consideraba fuera de la acción negativa de algún monopolio. En cambio, los defensores del proyecto de ley minera citaron ese debate frecuentemente para justificar las restricciones a las compañías extranjeras y enmarcar la reforma en una lucha contra los monopolios desde una dimensión internacional.

\section{La supresión del artículo 144}

Además de la oposición que tuvo el artículo 144 del proyecto de ley minera de 1908 entre el empresariado minero, las presiones para su eliminación también provinieron de los empresarios de otros sectores, quienes lo consideraron una amenaza, pues las restricciones a los extranjeros para la obtención de propiedades mineras podría extenderse hacia otras actividades. Para Daniel Guggenheim la reforma era un factor de incertidumbre en todos los negocios porque era posible que se implementaran medidas semejantes sobre otros tipos de propiedad, lo que significaría "la erección de una muralla china alrededor de la República que la separe del resto del mundo [...] un retroceso a los tiempos del obscurantismo..." ${ }^{77}$ El embajador mexicano en Estados Unidos, Enrique Creel, con enorme experiencia dentro de las redes de negocios entre mexicanos y es-

${ }^{56}$ Carlos Robles, “Las compañías extranjeras y el proyecto de ley minera. Séptima parte.”, El Tiempo, 16 de julio de 1908.

57 UIA, APD, f. 010803, carta de Daniel Guggenheim a Porfirio Díaz, Nueva York, 24 de julio de 1908.

ESTUDIOS DE HISTORIA MODERNA Y CONTEMPORÁNEA DE MÉXICO 55, enero-junio 2018, 121-157

DOI: http://dx.doi.org/10.22201/iih.24485004e.2018.55.63797 
tadounidenses, comunicó a Limantour que el proyecto de ley había causado alarma en Estados Unidos, que se temía que esos principios se aplicaran a otro tipo de propiedades y a negociaciones industriales y que el Departamento de Estado le había solicitado información al respecto. ${ }^{58}$ Desde Europa se recibieron noticias semejantes, que la reforma minera había generado sobresalto y que los inversionistas creían que anunciaba un cambio en la política liberal hacia los extranjeros, por lo que se pronosticaba una reducción en la inversión, especialmente entre el empresariado inglés. ${ }^{59}$ Para algunos, la generalización de las restricciones hacia los extranjeros tenía su origen en un sentimiento antiextranjero, sobre lo cual corrió mucha tinta en los periódicos. The Mexican Herald, que publicaba información financiera y comercial dirigida a la colonia estadunidense residente en la ciudad de México, pero que también era muy leído entre los funcionarios mexicanos, sostuvo que la ley minera reflejaba el antiextranjerismo prevaleciente en México, lo que reprodujeron otras publicaciones como The Mining World, de Chicago y Nueva York y The Engineering and Mining Journal. Opiniones contrarias circularon en El Imparcial o El Economista Mexicano, que se refirieron al ministro Molina como "la persona menos accesible a un mezquino sentimiento de hostilidad al extranjero...”"

La postura de Molina no tuvo un respaldo unánime entre el círculo gobernante, sino que poco después de la presentación pública del proyecto, en mayo de 1908, algunos aconsejaron la eliminación del artículo 144. En este sentido, The Mining World aseguró que, debido a las críticas y a "los sabios consejeros del Gobierno Mexicano", el proyecto de ley había "hecho sonar ya la hora de su muerte". ${ }^{61}$ Creel aseguró públicamente que el gobierno modificaría la ley, mientras que el influyente científico Pablo Macedo le recomendó a Limantour

${ }^{8}$ CEHM, AJYL, fondo CDLIV, rollo 52, carta de Enrique Creel a José Yves Limantour, Washington, 2 de agosto de 1908. El estudio clásico sobre los negocios de Creel y su vinculación con empresas y empresarios estadounidenses es el de Wasserman (1973, p. 279-319).

59 UIA, APD, f. 014265, carta de Luis T[ilegible] a Porfirio Díaz, París, 23 de septiembre de 1908.

60 "No hay sentimiento extranjero en México", en El Economista Mexicano, 4 de julio de 1908; “El gobierno y los capitales extranjeros", en El Imparcial, 27 de junio de 1908; "No hay sentimiento de antiextranjerismo", El Imparcial, 29 de junio de 1908.

${ }^{61}$ The Mining World, 13 de junio de 1908, citado El Economista Mexicano, 4 de julio de 1908. 
declarar que el gobierno reconsideraría el proyecto, pues en Nueva York había causado un desastre, a lo que el secretario de Hacienda contestó que se trataba "sólo de un proyecto elaborado en Ministerio de Fomento, que todavía no se discute en Consejo de Ministros". ${ }^{62}$ También el presidente de la colonia estadounidense en México, William Vernon Backus le expresó a Limantour que deseaba que no se aprobara el proyecto y le consultó si podía manifestar este deseo a quienes le preguntaran sobre la ley, con lo cual probablemente Backus buscaba que Limantour definiera su postura. ${ }^{63}$

Hacia finales de julio Molina, mantenía su defensa del proyecto y, en una carta que dirigió a The Mining and Scientific Press, de San Francisco, repitió una vez más los beneficios que atribuía a la reforma y subrayó que la ley no sería retroactiva. ${ }^{64}$ Sin embargo, el esfuerzo de Molina fracasó pues, a mediados de octubre, tras una reunión de cuatro horas entre Porfirio Díaz y su gabinete, se anunció la supresión de las restricciones para que los extranjeros adquirieran propiedades en México y también la responsabilidad civil de las compañías en caso de accidentes mineros. La Cámara Minera de México expresó su beneplácito y aseguró que el número de asociados se había incrementado, como un signo de aprobación a sus gestiones para la modificación del proyecto de ley minera. ${ }^{65}$ El proyecto revisado se envió al Congreso, fue aprobado en 1909 y la ley entró en vigor al año siguiente.

Rodolfo Reyes y Frederick Baker analizaron la nueva ley y concluyeron que la minería mexicana era un negocio atractivo y seguro para los inversionistas,

62 "It Will be modified. Anti-foreign mining measure not probable. Governor Creel's opinion", The Mexican Herald, 17 de junio de 1908; CEHM, AJYL, fondo CDLIV, rollo 50, telegrama de Pablo Macedo para José Yves Limantour, Nueva York, 17 de junio de 1908; telegrama de José Yves Limantour para Pablo Macedo, 17 de junio de 1908.

63 CEHM, AJYL, fondo CDLIV, rollo 55, Carta de William Vernon Backus a José Yves Limantour, México, 26 de agosto de 1908. Sobre las actividades de William Vernon Backus y sus vínculos con otros miembros de la comunidad norteamericana en México véase Schell (2001, p. 17-18, 118).

64 La carta de Olegario Molina, fechada el 20 de julio, fue publicada el 1 de agosto The Mining and Scientific Press. "La nueva Ley minera. Interesante carta del señor Ministro de Fomento", El Tiempo, 26 de agosto de 1908.

65 “La Cámara minera envió mensajes a Inglaterra y a los Estados Unidos”, El Imparcial, 16 de octubre de 1908. "Aumenta el número de socios de la Cámara Minera”, El Imparcial, 5 de diciembre de 1908. 
ya que mantenía los principios de la de 1892. Si bien esto es cierto, sobre todo porque quedaron fuera los cambios que se habían contemplado en el proyecto de ley de 1908, no debe pasarse por alto que la nueva ley significó un giro hacia un mayor intervencionismo del Estado, lo que se anunció desde los proyectos de ley de 1907 y 1908. La ley promulgada conservó varias disposiciones incluidas en el proyecto de 1908, tales como la ampliación de las competencias federales para la regulación de la propiedad minera y las operaciones mercantiles, las facultades de la Secretaría de Fomento sobre la inspección de las minas y suspensión de las labores, así como la desaparición de los contratos de exploración. Adicionalmente, la ley de 1909 introdujo la definición de dominio directo de la nación sobre el subsuelo y la adquisición de la propiedad minera a través de un título expedido por el Ejecutivo y no mediante un denuncio tramitado ante la Agencia de Minería, como había propuesto el proyecto de 1908. Al igual que en la ley de 1892, la propiedad caducaba solamente por la falta de pago del impuesto establecido. Por otro lado, la apreciación de Reyes y Baker era acertada en cuanto a la ausencia de restricciones al capital extranjero, pues se limitó a negar propiedades a los extranjeros en una faja fronteriza de $80 \mathrm{~km} .{ }^{66}$

La tranquilidad de analistas como Reyes y Baker sobre la continuidad de la ley de 1909 con respecto a la de 1892 fue temporal. Por un lado, la discusión sobre el artículo 144 no desapareció, ya que que de vez en vez alguien se refirió a su pertinencia o elogió a Olegario Molina por la defensa que hizo de la reforma. En un folleto anónimo que circuló poco después de la aprobación de la nueva ley minera, se insistió en que el análisis realizado por Molina había sido certero y llamaba a la implementación del artículo 144, "io ahora o nunca!", decía el autor. ${ }^{67}$ En la misma dirección, González Roa recomendó en 1915 una mayor vigilancia sobre las sociedades extranjeras y recordó el intento realizado con el proyecto de ley minera de 1908, aunque atribuía su fracaso a que Molina había cedido frente a los "especuladores extranjeros" y sus "cómplices mexicanos" ${ }^{68}$ Pero lo que reavivó el tema fue la revolución mexicana y en particular

\footnotetext{
${ }^{66}$ Reyes y Baker (1910, p. 15, 30-32).

67 “El artículo 144 del proyecto primitivo de la ley minera", en La nueva ley minera (1910, p. 597-613).

68 González (1975, p. 545).
} 
la legislación del periodo preconstitucional, específicamente el decreto emitido por Venustiano Carranza en agosto de 1916. Esta legislación obligó a las sociedades extranjeras a convertirse en empresas mexicanas y a los extranjeros a renunciar a sus derechos de extranjería y protección diplomática para la adquisición de terrenos baldíos o nacionales, fundos mineros, aguas de jurisdicción federal o permisos para la exploración y explotación de la riquezas naturales, como petróleo, productos forestales y pesqueros. Durante las discusiones en el Congreso Constituyente de 1916-1917 se planteó el problema acerca de cómo establecer límites a la concentración de la propiedad en manos de extranjeros y a la vez no cancelar el flujo de inversión extranjera. La asamblea se distinguió por la existencia de valores y preocupaciones que compartían sus miembros de tal manera que, de acuerdo con Ignacio Marván, un rasgo en común fue su "mexicanismo" y la desconfianza a los extranjeros, dado su convencimiento de que este grupo había recibido un trato privilegiado durante el porfiriato. ${ }^{69}$ Carranza planteó en la presentación de su anteproyecto de reformas a la Constitución de 1857 que la asamblea debía analizar si convenía que los extranjeros renunciaran expresamente a su nacionalidad para acceder a la propiedad y en el anteproyecto incluyó la incapacidad para que las sociedades anónimas adquirieran bienes raíces. La comisión que redacto el artículo 27, bajo la dirección de Pastor Rouaix, descartó la prohibición hacia las sociedades anónimas del anteproyecto y tampoco incorporó las propuestas de algunos diputados para que los extranjeros se naturalizaran como condición a la adquisición de bienes raíces, esto último porque "se cerraría en lo absoluto la entrada al país de capitales extranjeros”. Francisco Múgica manifestó que la naturalización era una idea inviable, pues "equivalía a la muralla china... aunque es patriótica”. Otro tema polémico fue si la obligación de los extranjeros para considerarse como nacionales respecto a los bienes adquiridos y que no invocaran la protección de sus gobiernos era suficiente para evitar conflictos diplomáticos. Algunos diputados opinaron que la nacionalidad era irrenunciable y que los gobiernos extranjeros no reconocerían esa disposición, pero finalmente se aceptó que la renuncia a los derechos de extranjería convenida

69 Marván (2011, p. xIX, xx) 
ante la Secretaría de Relaciones Exteriores era un contrato privado, que los gobiernos extranjeros no podrían desconocer..$^{70} \mathrm{El}$ artículo 27 estableció que solamente los mexicanos por nacimiento o por naturalización y las sociedades mexicanas podían obtener concesiones para la explotación de minas. El Estado reconocería el mismo derecho a los extranjeros que aceptaran considerarse nacionales con respecto a los asuntos derivados de la explotación de dichos bienes y no invocar la protección de sus gobiernos. ${ }^{71}$

Una parte de la crítica contra la Constitución de 1917 retomó argumentos que se habían escuchado durante la discusión en torno al artículo 144 del proyecto de ley minera de 1908, tales como que con esa medida México se alejaba de la tendencia que seguían las naciones civilizadas, que se paralizaría el flujo de capital extranjero y que las limitaciones pretendidas abrigaban un sentimiento antiextranjero. Así lo indicó Emilio Rabasa en su estudio acerca del impacto de la Constitución de 1917 sobre el régimen de propiedad, que realizó en ese año por encargo del petrolero Weetman Pearson, pues sostuvo que la tendencia en la legislación internacional consistía en que los extranjeros tuvieran los mismos derechos civiles que se les conferían a los nacionales, calificó a la Constitución tanto de anticapitalista como de antiextranjerista y previó la intervención diplomática como único remedio a la tiranía que veía en la Constitución..$^{72}$ Rodolfo Reyes, protagonista en la reforma a la ley minera y crítico del artículo 144 del proyecto de ley minera, actuó políticamente desde su exilio en España en contra de la Constitución de 1917. Pero también asumió esta postura Toribio Esquivel Obregón, tanto desde su exilio en Nueva York como a su regreso a México pues, a pesar de que había elogiado a Olegario Molina por el sentido del artículo 144, fue un crítico de la Constitución y en especial del artículo 27, porque consideraba que el predominio absoluto del Estado sobre los recursos naturales atropellaba el derecho individual y estorbaba a la iniciativa privada. ${ }^{73}$

70 Marván (2011, p. 1042-1055); Rouaix (1959, p. 155, 156).

${ }^{71}$ Sariego, et al. (1988, p. 61).

${ }^{72}$ En su momento, José Yves Limantour participó en los planes para publicar anónimamente el estudio de Rabasa, aunque no se concretó y el documento se perdió durante años, pero recientemente fue identificado y publicado. Rabasa (2017, p. 139, 170-180).

73 Garciadiego (2010, p. 560); Blanco (2012, p. 219-227). 


\section{Conclusión}

El intento por reformar la actividad de las sociedades extranjeras en la explotación minera de México, devela el interés del gobierno mexicano para la implementación de una estrategia económica que fortaleciera la conducción del Estado y al mismo tiempo mantuviera los beneficios asociados con la inserción de México en los flujos económicos globales. Sin embargo, la discusión que desencadenó evidencia la creciente dificultad del régimen para negociar con actores clave del proceso de modernización económica en curso, así como las diferencias entre el equipo gobernante sobre la manera de llevar a cabo tal negociación. El artículo 144 del proyecto de ley minera de 1908 fue percibido por el empresariado como una hostilidad, pero sobre todo como una medida incoherente, porque no tomaba en cuenta que México era un país deficitario en inversión y con un mercado de capitales poco desarrollado, de tal manera que insistieron en una política liberal y rechazaron el replanteamiento de las condiciones para el acceso a la propiedad minera, que se habían fijado en 1892. Algunos empresarios indicaron que las leyes mexicanas para la organización de sociedades mercantiles eran problemáticas para el desarrollo de la minería, lo que probablemente se planteó exageradamente durante el debate pero que, sin embargo, puede ser un signo adicional sobre lo inacabado de la modernización en la legislación económica de México. El seguimiento de esta problemática puede resultar útil, con la finalidad de examinar los desafíos que tenía la minería mexicana para su desempeño en el largo plazo.

La propuesta del artículo 144 fue un paso hacia el rompimiento con el liberalismo del siglo xix en materia de derechos de propiedad, mediante una mayor intervención del Estado y de nuevas reglas para la operación de empresas mineras extranjeras, como una forma de responder a problemáticas derivadas de la manera en que México se había insertado en la globalización, tales como la participación dominante del capital estadounidense y la existencia de una estructura industrial que incluía a grandes conglomerados minerometalúrgicos. La implementación de la reforma fue impracticable durante el porfiriato debido a la reacción del empresariado extranjero, que se manifestó en las expresiones de influyentes empresarios como Daniel Guggenheim, y del órgano de 
representación de los mineros, la Cámara Minera de México, que incluía a diversos representantes de las empresas extranjeras y a especialistas en la legislación económica de la época. La tensión entre el objetivo de acotar la influencia de los extranjeros en la propiedad minera y mantener el flujo de inversión se manifestó una vez más durante el Congreso Constituyente de 1916-1917, pues los debates revelan que algunos diputados defendieron medidas más extremas para condicionar el acceso a la propiedad, como la naturalización. La incorporación de las medidas que inspiraron al artículo 144 en la Constitución de 1917, está en consonancia con las modificaciones en el equilibrio de fuerzas que trajo la revolución mexicana y que condujo a una pérdida relativa de la influencia que habían ejercido los inversionistas extranjeros, cuyas consecuencias económicas se siguen debatiendo en la historiografía económica mexicana.

Fuentes

Archivos

Archivo José Yves Limantour, Centro de Estudios de Historia de México, CARSO (CEHM-AJYL).

Archivo Porfirio Díaz, Universidad Iberoamericana (APD-UIA)

The Nettie Lee Benson Latin American Collection, Texas University, Austin Texas (UT-NLBC).

Hemerografía

El Economista Mexicano

El Imparcial

El Tiempo

The Mexican Herald

Bibliografía

Bernstein, M. (1964). The Mexican Mining Industry 1890-1950. A Study of the Interaction of Politics, Economics and Technology. Nueva York: State University of New York. 
Blanco, M. (1995). Revolución y contienda política en Guanajuato, 1908-1913. México: El Colegio de México/Universidad Nacional Autónoma de México.

Blanco, M. (2012). Historia de una utopía. Toribio Esquivel Obregón (18641946). México: El Colegio de México/Universidad Nacional Autónoma de México.

CAhill, K. (1998). "The U.S. Bank Panic of 1907 and the Mexican Depression of 1908-1909”. The Historian 60 (n. 4), p. 795-811.

CÁrdenas, E. (2003). Cuando se originó el atraso económico de México. La economía mexicana en el largo siglo XIX, 1780-1920. Madrid: Biblioteca Nueva/Fundación José Ortega y Gasset.

CARMagnani, M. (2011). Los vectores de la cultura económica liberal en México. Economía y política. México y América Latina en la contemporaneidad. Antología de textos de Marcello Carmagnani (p. 171-195). México: El Colegio de México.

Carstensen, F. y D. Roazen (1998). "Mercados extranjeros, iniciativa interna y monocultivo: la experiencia yucateca, 1825-1903”, en J. Silva Riquer y J. López Martínez (coords.). Mercado interno en México. Siglos XVIII-XIX (p. 168-224). México: Instituto Mora/El Colegio de Michoacán/El Colegio de México/Universidad Nacional Autónoma de México, Instituto de Investigaciones Históricas.

Collins, Wayne (2013). "Trusts and the Origins of Antitrust Legislation”. Fordham Law Review 81 (5), p. 2279-2348.

Comín, F. (2014). Historia Económica Mundial. De los orígenes a la actualidad. España: Alianza Editorial.

Cossío DíAz, J. R. (2017). "El artículo 27: entre la civilización y la revolución”, en E. Rabasa Estebanell, El derecho de propiedad y la Constitución mexicana de 1917 (p. 35-81), edición de J. A. Aguilar Rivera. México: Fondo de Culturas Económica/Centro de Investigación y Docencia Económicas/Suprema Corte de Justicia de la Nación.

Chirino, J. (1999), Pozos, de coyotes, crac y optimismo: origen y clausura de la Bolsa de México, 1895-1896. Tesis de licenciatura en Economía, México, Instituto Tecnológico Autónomo de México. 
Garciadiego, J. (2010). "Los exiliados por la Revolución Mexicana”, en J. Garciadiego y E. Kourí (comps.), Revolución y exilio en la historia de México. Del amor de un historiador a su patria adoptiva. Homenaje a Friedrich Katz (p. 539-565). México: El Colegio de México/Universidad de Chicago, Centro Katz/Ediciones Era.

Garner, P. (2013). Porfirio Díaz. Del héroe al dictador: una biografía política ( $2^{\mathrm{a}}$ ed.). México: Planeta.

GARNER, P. (2013b). Leones británicos y águilas mexicanas. Negocios, política e imperio en la carrera de negocios de Weetman Pearson en México, 18891919. México: Fondo de Cultura Económica/Instituto Mora/El Colegio de México/El Colegio de San Luis.

Gómez-Galvarriato, A. y G. Recio (2003). El nacimiento de la sociedad anónima y la evolución de las organizaciones empresariales en México: 1886-1910 (Cuaderno de trabajo no. 279). México: Centro de Investigación y Docencia Económicas, División de Economía.

Gómez-Galvarriato, A. y A. Musacchio (2004). "Organizational Choice in a French Civil Law Underdeveloped Economy: Partnerships, Corporations and the Chartering of Business in Mexico, 1886-1910". Working Paper 05-O24, Harvard Business School.

Gómez-Galvarriato, A. (2014). "Modernización económica y cambio institucional: del porfiriato a la segunda guerra mundial”, en G. Márquez (coord.). Claves de la historia económica de México. El desempeño de largo plazo (siglos XVI-XXI) (p. 103-141). México: Fondo de Cultura Económica/Consejo Nacional para la Cultura y las Artes.

Gómez Serrano, J. (2004). "La familia Guggenheim y el desarrollo minero-metalúrgico de Aguascalientes, 1894-1911”, en C. Contreras Delgado y M. Gámez (coords.), Procesos y espacios mineros. Fundición y minería en el centro y noreste de México durante el porfiriato (p. 61-86). México: El Colegio de la Frontera Norte/Plaza y Valdés Editores.

GonZÁlEz RoA, F. (1975). "Notas sobre las reformas necesarias a la legislación sobre sociedades anónimas”, en F. González Roa, El problema ferrocarrilero y la compañía de los ferrocarriles nacionales de México ( ${ }^{\mathrm{a}}$ ed.). 
México: Ediciones de la Liga de Economistas Revolucionarios de la República Mexicana A. C.

Grunstein, A. (2012). Consolidados: José Yves Limantour y la formación de Ferrocarriles Nacionales de México. México: Consejo Nacional para la Cultura y las Artes.

HABER, S. (1999). "El crecimiento económico y la historiografía económica de la América Latina”, en S. Haber (ed.), Cómo se rezagó la América Latina. Ensayos sobre las historias económicas de Brasil y México, 180o-1914, (p. 9-46). México: Fondo de Cultura Económica.

HERRERA, I. y E. González (2004). Recursos del subsuelo, siglos XVI al XX. v. 10. México: Universidad Nacional Autónoma de México/Editorial Océano.

Hoernel, R. (1980). "Las grandes corporaciones y la política del gran garrote en Cuba y en México". Historia Mexicana xxx (n. 2), p. 209-246.

Joseph, G. (1992). Revolución desde afuera. Yucatán, México y los Estados Unidos, 1880-1924, México: Fondo de Cultura Económica.

Knight, A. (1996). La Revolución mexicana. Del porfiriato al nuevo régimen constitucional. v. I. México: Grijalbo.

KoLASKY, W. (2011). "Theodore Roosevelt and William Howard Taft: Marching Toward Armageddon”. Antitrust 25 (n. 2), p. 97-104.

KunTz, S. (2010). "De las reformas liberales a la Gran Depresión, 1856-1929", en S. Kuntz Ficker (coord.), Historia económica general de México. De la Colonia a nuestros días, (p. 305-352). México: El Colegio de México/Secretaría de Economía.

La reforma bancaria de 1908. Una discusión entre Toribio Esquivel Obregón y Joaquín Casasús. Estudio introductorio y selección de documentos de M. Blanco. México: Facultad de Economía, Universidad Nacional Autónoma de México, 2008.

La nueva ley minera y su reglamento, México, 1910.

Legislación Federal Complementaria del Derecho Civil Mexicano. Dirección y estudio preliminar del Lic. Jacinto Pallares. México: Tipografía Artística de Ramón F. Riveróll, 1897 
LieHR, R. y M. Torres (1998). "Las free-standing companies británicas en el México del porfiriato, 1884-1911”. Historia Mexicana XLVII (n. 3), p. 605-653.

Luna Argudín, M. (2006). El Congreso y la política mexicana (1857-1911). México: El Colegio de México/Fondo de Cultura Económica/Fideicomiso Historia de las Américas.

MARICHaL, C. (2010). Nueva historia de las grandes crisis financieras. Una perspectiva global, 1873-2008. México: Debate.

MÁrquez, G. (1998). "Tariff protection in Mexico, 1892-1910: ad valorem tariff rates and sources of variation", en J. Coatsworth y A. Taylor (eds.), Latin America and the world economy since 1800 (p. 407-442). Cambridge: Harvard University Press.

Marván, I. (comp.) (2005). Nueva edición del Diario de Debates del Congreso Constitutyente de 1916-1917, 3 v., México: Suprema Corte de Justicia de la Nación.

Memoria presentada al Congreso de la Unión por el Lic. Olegario Molina, Secretario de Estado y del Despacho de Fomento, Colonización e Industria de la República Mexicana correspondiente al ejercicio fiscal de 1908-1909. México: Imprenta y Fototipia de la Secretaría de Fomento, 1910.

Meyer Cosío, F. J. (1998). La minería en Guanajuato. Denuncios, minas y empresas (1892-1913). México: El Colegio de Michoacán/Universidad de Guanajuato.

O’ ROURKe, K. y J. Williamson (2001). Globalization and History. The Evolution of a Nineteenth-Century Atlantic Economy. United States of America: Massachusetts Institute of Technology Press.

PARRA, A. y P. Riguzzi (2008). Capitales, compañías y manías británicas en las minas mexicanas, 1824-1914. Historias 71, p. 35-59.

Primer proyecto de ley minera presentado al señor ministro de fomento por los señores ingenieros Eduardo Martínez Baca y Joaquín Ramos Lis, y licenciados Manuel Ortega Espinosa, José Luis Requena y Rodolfo Reyes. México: Imprenta y Librería de Inocencio Arriola, 1909. 
REYES, R. (1901). La agricultura y la ley minera. Tesis presentada por el alumno Rodolfo Reyes, en su examen general de abogado. México: Escuela Nacional de Jurisprudencia, Monterrey/Imprenta del Gobierno en Palacio.

REyes, R. y F. F. Baker (1910). The mining laws of Mexico. Containing a translation of the mining law and regulations and of the mining tax law and regulations; with an introduction, commentary, cross references and alphabetical index. México: The American Book and Printing Company.

Riguzzi, P. (2004). "Legislación y organización jurídica de la economía mexicana, 1867-1910”, en M. Téllez y J. López Fontes (comp.), La legislación mexicana de Manuel Dublán y José María Lozano (p. 157-188). México: Suprema Corte de Justicia de la Nación/Tribunal Superior de Justicia del Estado de México/El Colegio de México/Escuela Libre de Derecho.

Riguzzi, P. (2009). "From globalisation to Revolution? The porfirian political economy: an essay on issues and interpretations". Journal of Latin American Studies v. 41 (n. 2), p. 347-368.

Rouaix, P. (1959). Génesis de los artículos 27 y 123 de la Constitución Política de 1917. México: Instituto Nacional de Estudios Históricos de la Revolución Mexicana.

SÁNCHEZ RANGEL, O. (2015). "Inversión extranjera y minería. La reactivación de la producción de plata en el Guanajuato porfiriano”, en M. Luna Argudín y M. José Rhi Sausi (coords.), Repensar el siglo XIX. Miradas historiográficas desde el siglo $x x$ (p. 188-215). México: Secretaría de Cultura/Universidad Autónoma Metropolitana/Fondo de Cultura Económica.

SARIEgo, J. L., L. Reygadas, M. Á. Gómez y J. Farrera (1998). El Estado y la minería mexicana, política, trabajo y sociedad durante el siglo xx. México: Fondo de Cultura Económica/Secretaría de Energía, Minas e Industria Paraestatal/Instituto Nacional de Antropología e Historia, Comisión de Fomento Minero.

Schell, W. (2001). Integral outsiders. The american colony in Mexico city, 1876-1911. Wilmington: Scholarly Resources.

URIBE, J. A. (2010). Historia económica y social de la Compañía y Cooperativa Minera “Las Dos Estrellas”, en El Oro y Tlalpujahua, 1898-1959. México: 
Universidad Michoacana de San Nicolás de Hidalgo, Consejo Superior de Investigaciones Científicas de España.

WASSERMAN, M. (1973). "Oligarquía e intereses extranjeros en Chihuahua durante el porfiriato”. Historia Mexicana XXII (n. 3), p. 279-319.

Wasserman, M. (2015). Pesos and politics. Business, elites, foreigners, and government in Mexico, 1854-1940. Stanford, California: Stanford University Press.

Weiner, R. (2004). Race, Nation and Market. Economic Culture in Porfirian Mexico. Tucson: The University of Arizona Press.

ZuLETA, M. C. (2000). "La Secretaría de Fomento y el fomento agrícola en México, 1876-1910: la invención de una agricultura próspera que no fue”. Mundo Agrario. Revista de Estudios Rurales 1 (1), s/p.

Zuleta, M. C. (2006). De cultivos y contribuciones. Agricultura y Hacienda estatal en México en la "Época de la Prosperidad". Morelos y Yucatán 1870-1910, México: Universidad Autónoma Metropolitana-Iztapalapa. 